\title{
Ecos pirandellianos en el pensamiento de Unamuno
}

\author{
Armin MOBARAK \\ Universidad Complutense de Madrid \\ arminmobarak@gmail.com
}

Mi teatro es serio. No es ciertamente un teatro cómodo. Teatro dificil. Teatro peligroso. Nietzsche decía que los griegos levantaban blancas estatuas sobre el abismo, para ocultarlo.

Yo, en cambio, las derribo para revelarlo.

Luigi Pirandello

\section{RESUMEN}

En este trabajo nos centramos en la influencia de Luigi Pirandello sobre Miguel de Unamuno. Y pretendemos analizar las semejanzas entre el cuento pirandelliano titulado $L a$ tragedia de un personaje y la novela de Unamuno, Niebla. Además, comentamos las analogías conceptuales de dos dramas del autor español, es decir, El otro y El hermano Juan, con la filosofía de Luigi Pirandello. Finalmente y a modo de conclusión, nos damos cuenta de que los tópicos pirandellianos como la locura frente a la cordura, el ser versus el parecer, la coexistencia entre la realidad y la ficción y la técnica del teatro dentro del teatro aparecen en ambos textos del autor español de forma unánime y coherente.

Palabras clave: Pirandelli, Unamuno, Drama, La tragedia de un personaje, Niebla.

\begin{abstract}
In this paper I focus on the influence of Luigi Pirandello on Miguel de Unamuno. The first similarities between these two writers appear on a Pirandellian short story titled $A$ character's tragedy and Unamuno's novel, Niebla. Furthermore, I analyze two dramas of the Spanish author, El hermano Juan and El otro and I remark on its commonalities with the philosophy of Luigi Pirandello. Finally, I realize that the Pirandello's topics such as madness versus sanity, to be versus to seem, the coexistence of reality and fiction and the art of play within a play appear in both texts of the Spanish author unanimously and consistently.
\end{abstract}

Keywords: Pirandelli, Unamuno, Drama, A character's tragedy, Niebla.

Sumario: 1. Introducción, 2. Niebla, 3. El otro, 4. El hermano Juan o el mundo es teatro, 5. Conclusiones. 


\section{Introducción}

En el presente trabajo, como se puede deducir de su título, nos vamos a ocupar de la influencia del gran escritor italiano del siglo pasado, Luigi Pirandello, sobre el pensador español, Miguel de Unamuno. Un tema que desde el segundo decenio del siglo XX hasta hoy en día ha sido el centro de muchos debates académicos y periodísticos. La polémica surgió a raíz de la publicación de Seis personajes en busca de autor y Niebla, y fue tan sonada que el mismo don Miguel escribió un artículo titulado «Pirandello y yo», publicado el 15 de julio de 1923 en La Nación, en el que negaba cualquier tipo de influencia:

Es un fenómeno curioso y que se ha dado muchas veces en la historia de la literatura, del arte, de la ciencia o de la filosofía, el que dos espíritus, sin conocerse ni conocer sus sendas obras, sin ponerse en relación el uno con el otro, hayan perseguido un mismo camino y hayan tramado análogas concepciones o llegadas a los mismos resultados. Diríase que es algo que flota en el ambiente ${ }^{1}$.

Esta controversia entre los estudios y la postura del propio Unamuno nos llevó a indagar sobre la cuestión para intentar encontrar la verdad de esta disputa intelectual. Para ello, acudimos directamente a los textos de ambos autores y procedimos a contrastar sus semejanzas.

Bien es verdad que el drama más famoso de Pirandello salió a la luz siete años (1921) después de que Unamuno publicase su nivola (1914). No obstante, la crítica, de forma unánime, siempre ha hablado de las analogías entre Niebla y Seis personajes en busca de autor ${ }^{2}$. Estas comparaciones se establecen por primera vez en el país natal de Pirandello, donde la prensa italiana habla paralelamente de ambos autores debido a la versión italiana de Niebla. ${ }^{3}$

Unamuno opinaba que esta postura de la prensa se derivaba de la cercanía que observaron los críticos italianos entre las ideas de su texto y Seis personajes en busca de autor. Sin embargo, a mi juicio, la obra más análoga del repertorio pirandelliano con la novela unamuniana es La tragedia de un personaje, un cuento corto que se publica en 1911 y asimismo formará parte de una colección de relatos que saldría a la luz en 1922, bajo el título Cuentos para un año.

\section{Niebla}

La tragedia de un personaje trata de un autor que hace varias entrevistas todos los domingos a unos personajes con el fin de encontrar la historia adecuada para su próxima novela. En una de estas entrevistas aparece un personaje llamado Dr. Fileno, que está en desacuerdo con el final de la novela que protagonizó. Él pide a

${ }^{1}$ M. Unamuno (1995), p. 305.

${ }^{2}$ Ver L. M. Carreto Bautista y O. M. Sota Gómez (2005) y C. L. Ferraro (2005).

${ }^{3}$ M. Unamuno (1995), pp. 305-309. 
nuestro autor que escriba otro final para este libro (obra de otro autor) y que no le deje abandonado al igual que el escritor de la novela. El desacuerdo y la petición del personaje crean una discusión existencialista entre el autor y él. Este pasaje nos recuerda a una escena de Niebla en la que Augusto Pérez tiene una semejante entrevista con su creador y se rebela contra el autor-personaje.

Recordemos que Niebla se publica en 1914, es decir, tres años más tarde que el relato de Pirandello. Por otra parte y según el mismo autor bilbaíno: «[...] soy curioso y diligente observador de la vida italiana...» ${ }^{4}$; como consecuencia de esta curiosidad, no sería de extrañar que Unamuno hubiera conocido el relato de Pirandello. Pero, incluso si tomamos el ejemplo de Niebla, creo que la deuda más nítida puede rastrearse, más que en detalles argumentales, en la filosofía pirandelliana que contiene. Me refiero a la forma y la estructura según las cuales se comportan los personajes. Augusto Pérez es una persona sin norte, sin motivación. En la apertura de la novela ni siquiera sabe adónde se dirige. Según su filosofía, la vida es un juego y una voluntad superior a la suya le dicta lo que tiene que hacer y decir. Incluso llega a decir que la «palabra se hizo para exagerar sensaciones e impresiones todas», y añade que la «única verdad es el hombre fisiológico, el que no habla, el que no miente ${ }^{5}$. En otras palabras, la apariencia es falsa y la verdad se esconde en la idea. Las palabras de Augusto son afines a la cosmovisión de Pirandello en la que los personajes son más verdaderos que las personas porque son criaturas que nacen de la imaginación.

Si nos fijamos en los protagonistas, Augusto Pérez presenta muchas afinidades con el Dr. Fileno. Ambos hablan de la inmortalidad de los entes de ficción, afirmando que el que nace personaje puede reírse de la muerte porque es inmortal. Respecto a este tema, entre el texto italiano y Niebla hay algunos pasajes con unas concomitancias filosóficas y conceptuales tan precisas que nos permiten plantear la idea de la influencia de Pirandello sobre Unamuno. Observen, por ejemplo, la semejanza de estos tres pasajes:

DR. FILENO. [...] ¡Perdóneme usted! ¡Nadie puede saber mejor que usted que nosotros somos seres vivos, más vivos que quienes respiran y llevan ropas; quizás menos reales, pero más verdaderos! [...] Quien nace personaje, quien tiene la ventura de nacer personaje vivo, puede reírse hasta de la mismísima muerte. ¡Ya no muere! ¡Morirá el hombre, el escritor, instrumento natural de la creación; la criatura ya no muere ${ }^{6}$.

AUGUSTO PÉREZ. ¡Yo no puedo morirme; sólo se muere el que está vivo, el que existe, y yo, como no existo, no puedo morirme..., soy inmortal! No hay

\footnotetext{
${ }^{4}$ M. Unamuno (1995), p. 305.

${ }^{5}$ M. Unamuno (1995), pp. 147-148.

${ }^{6}$ L. Pirandello (2002), pp. 322-323.
} 
inmortalidad como la de aquello que, cual yo, no ha nacido y no existe. Un ente de ficción es una idea, y una idea es siempre inmortal... ¡Soy inmortal! ¡Soy inmortal! ${ }^{7}$

AUGUSTO PÉREZ. No sea, mi querido don Miguel — añadió-, que sea usted y no yo el ente de ficción, el que no existe en realidad, ni vivo, ni muerto... No sea que usted no pase de ser pretexto para que mi historia llegue al mundo...

[...] ¿No ha sido usted el que no una sino varias veces ha dicho que Don Quijote y Sancho son no ya tan reales, sino más reales que Cervantes?

[...] Cuando un hombre dormido e inerte en la cama sueña algo, ¿qué es lo que más existe, él como conciencia que sueña, o su sueño? ${ }^{8}$

Las palabras de Fileno nos dejan sorprendidos cuando las comparamos con las opiniones de Augusto Pérez. Ambos consideran que los personajes son menos reales pero más verdaderos, como las ideas, y añaden que son inmortales porque no pertenecen al mundo material. Aparte de coincidir en sus pensamientos, Augusto repite literalmente lo que había pronunciado el protagonista de La tragedia de un personaje, una influencia que hasta hoy, que sepamos, y por lo menos en la hispanística, ha pasado desapercibida a la crítica.

Por otra parte, algunos personajes de Niebla como Víctor Goti y Unamuno son actores y espectadores al mismo tiempo. Goti es el autor del prólogo y el amigo de Augusto Pérez. Está dentro y fuera de la historia de una manera mágica, por lo tanto, es capaz de interactuar con los entes de ficción y observar sus decisiones al mismo tiempo. Esta característica se deja ver también en La tragedia de un personaje y Seis personajes en busca de autor. Este juego de sombras consiste en borrar la línea que divide la realidad de la ficción. Ambos autores emplean la metaficción en la que la frontera realidad-ficción y el pacto de lectura de ésta se ven quebrantadas. A través de este recurso narrativo y teatral, tanto Pirandello como Unamuno proporcionaban a sus dramas una buena dosis de ambigüedad y confusión.

Esta proximidad técnica y filosófica puede remontarse, quizá, a las fuentes literarias de las que se nutren ambos autores. Conviene recordar que los dos se dejan influir especialmente por tres grandes figuras de la literatura universal: Miguel de Cervantes, William Shakespeare y Pedro Calderón de la Barca. Estos tres escritores fueron los primeros en contemplar la vida como una ficción y como un escenario para la comedia divina. Dicha tendencia aparece de forma sutil y algunas veces muy clara en la mayor parte del repertorio dramático de Luigi Pirandello, como en Seis personajes en busca de autor (1921), Vestir al desnudo (1922), Cada cual a su manera (1924); y también en la obra de Unamuno, en casos como Amor y

\footnotetext{
${ }^{7}$ M. Unamuno (1995), p. 270.

${ }^{8}$ M. Unamuno (1995), pp. 261-262.
} 
pedagogía (1902), Vida de Don Quijote y Sancho (1905), y sobre todo en Niebla (1914).

Unamuno, en el manifiesto literario de «Pirandello y yo», expresa claramente la simpatía que siente por el autor siciliano y, al mismo tiempo, intenta huir de la larga sombra que aquel proyecta sobre él. Esta sombra, finalmente, captura a Unamuno en varias obras, y por mucho que afirme que es «algo que flota en el ambiente», el desarrollo de las ideas es profundamente cercano y revela una misma concepción literaria y filosófica. Aquí comentaremos dos obras suyas en las que los ecos pirandellianos suenan con más fuerza.

\section{El otro}

El otro, publicado en 1926, comparte las principales ideas del drama titulado Así es (si asi os parece) de Pirandello (1917). El texto italiano narra la complicada situación del Sr. Ponza, que ha perdido a casi todos sus parientes en un terremoto. Este se muda a una ciudad de provincias para dejar atrás todos los malos recuerdos del pasado y empezar una nueva vida. Pero la gente curiosa de su alrededor no le deja en paz y le causa molestias, preguntándole sobre la relación extraña que mantiene con su suegra, la Sra. Frola. El Sr. Ponza afirma que hace cuatro años que murió la hija de la Sra. Frola (su primera mujer), y se quedó viudo. Y añade que desde hace dos años está casado con otra mujer. La historia se complica cuando la suegra da su versión de los hechos. Ella dice que la actual mujer de Ponza es la misma mujer y por tanto su hija, pero él, por la pérdida de memoria, no puede reconocerla. Y aún se complica más cuando el lector/espectador cobra conciencia de que no puede averiguar quién miente y quién no. Ante esta situación, la última persona que podría aclararlo todo es la mismísima $\mathrm{Sr}^{\mathrm{a}}$. Ponza, una figura misteriosa que nunca se ha dejado ver en la ciudad. En la última escena aparece ella y pone el punto final a esta confusión complicándola aún más:

\footnotetext{
SEÑORA PONZA. (Hablando con lentitud y recalcando las palabras.) ... ¿Qué? ¿La verdad? Pues no hay más que esta: que yo soy, en efecto, la hija de la señora Frola...

[...] (Rápida, mismo juego.) ... y la segunda mujer del señor Ponza...

[...] y para mí ninguna de las dos, ninguna ${ }^{9}$.
}

Estas palabras tan extrañas de la señora Ponza nos dejan sorprendidos y perdidos a primera vista. Nunca se puede averiguar cuál es la verdad. El mensaje que pretende transmitirnos el autor es que no hay ninguna verdad absoluta.

Se puede realizar otra lectura de esta pieza partiendo de la psicología de los personajes. Me parece que los temas del álter ego y el trastorno de identidad

\footnotetext{
${ }^{9}$ L. Pirandello (1958), p. 84.
} 
disociativo ${ }^{10}$ son las claves para entender la comedia. Pero ¿de qué manera? El trastorno de identidad disociativo consiste en la existencia de dos o más personalidades en una sola persona. La señora Ponza es un buen ejemplo de este trastorno. Ella tiene otro yo, o más bien, otros yoes: es la segunda mujer y la hija, y dice que no es ninguna de ellas. Podríamos decir que por una parte, el drama gira en torno a esta patología. $\mathrm{O}$, al menos, nos deja parcialmente con la idea de que los personajes de esta historia sufren algún trastorno mental. Por lógica, la señora Ponza no puede ser al mismo tiempo la segunda mujer y la hija de la Sra. Frola, pese a su reconocimiento.

Por otra parte, sería posible plantear otra hipótesis sobre el señor Ponza y la señora Frola: uno de ellos podría padecer del síndrome de Frégoli, un trastorno delirante que consiste en creer que las personas conocidas tienen otra identidad. De hecho, el señor Ponza, indirectamente, señala a la suegra con esta enfermedad, cuando dice que un día estaba dando un paseo con su segunda mujer y de repente la señora Frola los vio por el balcón y, desde este instante, pensó que esta mujer era la misma hija suya. La suegra comenta otra historia que permite atribuirle el mismo trastorno al Sr. Ponza. Según ella, por las presiones causadas por parte del Sr. Ponza, su hija necesitaba estar un tiempo ingresada lejos de él en un hospital mental. Cuando ella volvió, el señor Ponza pensó que era otra mujer y nunca ha dejado de pensarlo. De este modo, el hombre también puede padecer el mismo mal.

Todas estas reflexiones son posibles gracias al contenido complicado e interesante de esta producción pirandelliana. Bien sabemos que el propósito del autor fue hacernos entender lo siguiente: la verdad absoluta no existe, cada cual lo percibe a su manera. La señora Ponza simboliza esta verdad y la imposibilidad de conocerla. Uno de los personajes que más nos hace recordar esta cosmovisión es Laudisi (el representante de las ideas pirandellianas), quien insiste constantemente en que no hay ninguna verdad absoluta, sino relativa.

SIRELLI. ¿Y entonces ninguno de los dos está loco? ¡Pero uno de los dos tiene que estarlo, por Dios!

LAUDISI. ¿Y cuál de los dos? Vosotros no podéis afirmarlo, como no puede afirmarlo nadie. Y no ya porque esos datos de hecho, que vosotros andáis buscando, hayan sido anulados..., desparramados o destruidos..., por un accidente cualquiera..., un incendio, un terremoto..., no, sino porque ellos los han anulado dentro de sí, en su alma, ¿queréis comprenderlo?, creándose, ella a él o él a ella, un fantasma que tiene la misma consistencia que la realidad en la que ellos viven, ya de común acuerdo, pacificados. Y esa realidad suya no podrá ser destruida por ningún documento, porque ellos respiran dentro de la misma, la ven, la oyen, la tocan... Para vosotros, a lo sumo, podría servir el documento para quitaros una

\footnotetext{
${ }^{10}$ La existencia de dos o más identidades o personalidades en un individuo, cada una con su propio patrón de percibir y actuar con el ambiente.
} 
estúpida curiosidad. Os falta, y heos condenados al maravilloso suplicio de tener delante, al lado, aquí al fantasma y aquí la realidad, y de no poder distinguir la una del otro ${ }^{11}$.

En la obra de Unamuno titulada El otro nos encontramos con muchas analogías con Así es... La figura del Ama nos habla también de esta verdad enigmática:

AMA: ¿La solución pública? Es la que menos debe importarnos. ¡Quédese cada cual con la suya y... en paz! [...] Yo no sé quién soy, vosotros no sabéis quiénes sois, el historiador no sabe quién es, no sabe quién es ninguno de los que nos oyen $^{12}$.

La obra de Unamuno también comparte una psicología idéntica a Así es..., puesto que existen también estos dos trastornos mentales en el drama. El protagonista de El otro, tras la muerte de su hermano, piensa que es Cosme y Damián, ambos hermanos y ninguno al mismo tiempo, de forma pareja a la señora Ponza. Laura y Damiana (las esposas de los hermanos) piensan, por su lado, que el superviviente (El Otro) es el hermano de su marido. Ellas sufren de idéntica patología a la padecida por el señor Ponza y la señora Frola, esto es, el síndrome de Frégoli. Podemos observar, en consecuencia, que ambas obras poseen la misma mirada psicológica en cuanto a sus personajes. No conviene olvidar, tampoco, que Enrique $I V$ también comparte los mismos aspectos psicológicos con El otro ${ }^{13}$.

Además de este aspecto, el tema del álter ego se deja notar claramente por el uso del espejo en ambas producciones. Laudisi por una parte y el protagonista de $E l$ otro por otra:

LAUDISI. (Paseando un poco por el estudio, riéndose para sí mismo y moviendo la cabeza; después se detiene delante del gran espejo de encima de la repisa de la chimenea, mira su propia imagen y habla con ella.) ¡Oh, querido! ¿Cuál de nosotros dos está loco? (Levanta una mano con el índice apuntando contra su imagen, la que, a su vez, apunta con el índice contra él. Vuelve a sonreír y luego.) Sí, lo sé: yo digo «tú», y tú con el índice me indicas a mí... ¡Bueno, así es como a tú por tú, nos conocemos bien nosotros dos! Lo malo es que los demás no te ven como yo te veo. ¿Y entonces, querido, en qué te conviertes tú? Digo, para mí, que aquí, frente a ti, me veo y me toco..., tú..., para como te ven los demás..., ¿en qué te conviertes?... ¡En un fantasma, querido, en un fantasma! Y, sin embargo, ¿ves a estos locos? Sin preocuparse del fantasma que llevan consigo, en sí mismos, van corriendo, llenos de curiosidad, detrás del fantasma de otros ${ }^{14}$.

${ }^{11}$ L. Pirandello (1958), p. 47.

${ }^{12}$ M. Unamuno (1992), p. 98.

${ }^{13}$ Ver A. Martínez-Peñuela Virseda (1996).

${ }^{14}$ L. Pirandello (1958), p. 50. 
En el fondo de la escena, un espejo de luna y de cuerpo entero, tapado por un biombo; El Otro se pasea cabizbajo y gesticulando como quien habla para sí, hasta que al fin se decide, separa el biombo y se detiene ante el espejo, crúzase de brazos y se queda un momento contemplándose. Se cubre la cara con las manos, se las mira, luego se las tiende a la imagen espejada como para cogerla de la garganta, mas al ver otras manos que se vienen a él, se las vuelve a sí, a su propio cuello, como para ahogarse. Luego, presa de grandísima congoja, cae de rodillas al pie del espejo, y apoyando la cabeza contra el cristal, mirando al suelo, rompe a sollozar ${ }^{15}$.

El espejo es el símbolo que nos muestra nuestro otro yo, que siempre está escondido en ambas piezas; es, si se quiere, el revelador de los secretos humanos y también desenmascara la esencia profunda del ser. La presencia del espejo es más destacada en la producción del autor español por las condiciones mentales del personaje. Él, enloquecido por asesinar a su hermano, huye de su imagen y de su rostro verdadero porque cada vez que se ve a sí mismo ve al otro, y el trauma de la identidad le vuelve a perturbar. En cambio, Laudisi es consciente de la existencia del otro yo, y lo tiene conocido y harto dominado.

Como observamos, el drama de Unamuno converge perfectamente con Así es (si así os parece), una década después de la publicación de ésta.

\section{El hermano Juan o el mundo es teatro}

En esta obra de 1929, Unamuno retoma el mito del famoso Don Juan desde otro ángulo. El hermano Juan mezcla la realidad con la ficción y las personas con los personajes. El protagonista, Juan, es la versión envejecida del mítico conquistador sevillano que, a estas alturas de su vida, está cansado de su pasado. Para él la verdadera vida es el teatro y como dice el personaje «el buen actor es el que se conduce en su casa — tal yo aquí_ y en la calle como en escena».

JUAN. Pero ¿no es esto (señalando el escenario) vivir?

ANTONIO. Hacer que se vive... y hacer por la vida...

JUAN. ¡Es igual! ¡Y qué empeño en alambicarla!

ANTONIO. Siempre tienes presente al público...

JUAN. ¡De él vivo! ¡En él vivo!

ANTONIO. Ello te quita naturalidad.

ANTONIO. El buen actor es el que se conduce en escena como en su casa o en la calle...

JUAN. Al revés; el buen actor es el que se conduce en su casa - tal yo aquí- y en la calle como en escena... ¡Todo es arte! Y más el vivir... ${ }^{16}$.

\footnotetext{
${ }^{15}$ M. Unamuno (1992), p. 79.

${ }^{16}$ M. Unamuno (1992), p. 169
} 
El Don Juan unamuniano es una extraña mezcla entre el ser y el parecer; es las dos cosas y ninguna. Según la ideología de nuestro Don Juan, el mundo es un escenario y cada uno nace con su papel en la cuna: «[...] En este teatro del mundo, cada cual nace condenado a un papel, y hay que llenarlo so pena de vida...». ${ }^{17}$ No creo que este comentario nos sea ajeno conociendo la influencia de Calderón en ambos autores, pues tiene fuertes reminiscencias de El gran teatro del mundo. Además, nos recuerda también las palabras del personaje del Dr. Fileno y el padre, quienes valoraban y apreciaban a los seres que nacían personajes y afirmaban que estos seres nunca morirán puesto que son productos de la imaginación e inmortales.

La obra comenta las últimas hazañas del viejo Juan en un convento donde intenta ayudar a las damas, al contrario de lo que hizo en el pasado. Tras la muerte de Don Juan vuelve a resonar una de las ideas principales de pirandello en cuanto a la inmortalidad de los entes de ficción: «Don Juan es inmortal, como el teatro». En la versión unamuniana del mito de Don Juan, el protagonista es consciente de su naturaleza como un personaje teatral y, por lo tanto, no teme a la muerte al contrario de los donjuanes que hemos conocido en la tradición literaria.

En 1924, es decir, cinco años antes de la publicación de El hermano Juan, Pirandello en Cada cual a su manera nos da una imagen del teatro muy semejante a la que dibuja Unamuno en su texto, donde considera el teatro más verdadero que la vida: «El teatro es la primera de las verdades..., la más verdadera..., no la que se ve, sino la que se hace... ${ }^{18}$. Y es que Cada cual a su manera es una obra muy completa, en la cual autor el introduce, desde el principio, el recurso del teatro dentro del teatro. Por tanto, tenemos dos niveles de realidad y de imaginación en la producción:

- En el primer nivel nos encontramos al Pirandello personaje, que decide escribir una pieza teatral inspirada en el suicidio de un famoso escultor llamado Giacomo La Vela, causado por la traición de su prometida, la famosa actriz Amelia Moreno, con su amante Barón Nuti, separados después por esta tragedia.

- El segundo nivel sería la representación de ese drama, en la que los dos amantes están entre los espectadores de la obra contemplando su vida en el escenario. Se encuentran así los dos niveles de ficción y se reencuentran los dos amantes, que verán representado un desenlace feliz de su historia de amor.

En el último acto se produce el inevitable choque de ambos mundos: Amelia Moreno, irritada desde el primer momento de la función, pierde finalmente la paciencia después de ver cómo se termina la obra, y entra en el escenario pese a la resistencia de sus amigos gritando al director: «¡No! ¡No es verdad! ¡Para mí ha sido horroroso, horroroso, verme representada en ese escenario! ¿Yo, yo abrazar a ese hombre?». Por otro lado, Barón Nuti también sube al escenario y se acerca a ella pidiéndole que hagan lo mismo que vieron en la obra (abrazarse y permanecer

\footnotetext{
${ }^{17}$ M. Unamuno (1992), p. 133.

${ }^{18}$ M. Unamuno (1992), p. 201.
} 
unidos): «¡Es verdad! ¡Es verdad que debemos sufrir juntos el castigo! ¿No lo has oído? ¡Ya todos lo saben! ¡Vámonos, ven!» ${ }^{19}$. Ella se resiste al principio, pero acaba resignada ante la superioridad de la ficción sobre su propia realidad; esa es la esencia del arte pirandelliano.

Mientras ocurre este escándalo en la sala, los espectadores, sorprendidos por lo que han visto sobre el escenario, no consiguen asimilarlo. Uno de los presentes en la sala intenta explicar lo ocurrido con estas palabras: «No, señores míos, es lo más natural del mundo. Se han visto en un espejo y se han rebelado, especialmente ante este último gesto» ${ }^{20}$.

Tanto el Don Juan de Unamuno como los protagonistas del drama de Pirandello tienen como referencia a los personajes de teatro. Es decir, los seres humanos se dejan llevar por los personajes ficticios. El protagonista de El hermano Juan vive una constante representación del personaje teatral que fue don Juan Tenorio, y Amelia Moreno y su amante, tras observar el final del espectáculo, optan por una vida que vieron sobre el escenario ${ }^{21}$.

\section{Conclusiones}

En ambos textos nos damos cuenta de que el teatro es más verdadero que la vida y más real que la realidad. Tanto Pirandello como Unamuno estan convencidos de que la vida es una máscara y el teatro es el rostro que se esconde debajo de ella. La vida es la apariencia y el teatro es la esencia. En El hermano Juan el protagonista nos lo deja muy claro: para él el escenario es el sendero de la vida verdadera y el mundo es un espectáculo en el que los seres humanos nacen para actuar:

JUAN. ¿Existo yo? ¿Existes tú, Inés? ¿Existes fuera del teatro? ¿No te has preguntado nunca esto? ¿Existes fuera de este teatro del mundo en que representas tu papel como yo el mío? ¿Existís, pobres palomillas? ¿Existe don Miguel de Unamuno? ¿No es todo esto un sueño de niebla? Sí, hermana, sí, no hay que preguntar si un personaje de leyenda existió, sino si existe, si obra. Y existe Don Juan y Don Quijote y don Miguel y Segismundo y Don Álvaro, y vosotros existís, y hasta existo yo..., es decir, lo sueño..., Y existen todos los que nos están aquí viendo y oyendo, mientras lo estén, mientras nos sueñen... ${ }^{22}$.

Si tenemos en cuenta todas las analogías en ambas piezas, no podemos ignorar la influencia que ejerció Pirandello sobre Unamuno. Está claro que la influencia ha sido algo tardía, es decir, a partir de la segunda década del siglo XX. Opino, sin embargo, que la huella de Pirandello es obvia, pese a las reticencias iniciales de Unamuno, quien, a la altura de 1923, evitaba comparaciones y comentarios que

\footnotetext{
${ }^{19}$ L. Pirandello (2004), pp. 245-246.

${ }^{20}$ L. Pirandello (2004), p. 247.

${ }^{21}$ Ver Mobarak (2013).

${ }^{22}$ M. Unamuno (1992), p. 194.
} 
evidenciaran su cercanía con el autor transalpino. Los tópicos pirandellianos como la locura frente a la cordura, el ser versus el parecer, la coexistencia entre la realidad y la ficción, la técnica del teatro dentro del teatro aparecen en El otro y El hermano Juan de forma unánime y coherente. No obstante, cuando hablamos de Miguel de Unamuno no se le puede atribuir fácilmente el calificativo de «influido», porque el autor bilbaíno era capaz de filtrar todo lo que le llegaba por su filosofía e ideología y, de esta manera, su producción artística gozaba de una seña de identidad muy particular y completamente unamuniana.

\section{OBRAS CITADAS}

\section{FUENTES PRIMARIAS}

PIRANDELlo, Luigi: Obras escogidas II. Así es (si así os parece); Cada cual a su manera; Piénsalo, Santiaguito; El placer de ser honrado; El hombre, la bestia y la virtud; Como antes, mejor que antes; El gorro de cascabeles; La razón de los demás; Todo como se debe; Cada cual en su papel, Madrid, Aguilar, 1958.

: La tragedia de un personaje, Barcelona, El Acantilado, 2002.

: Seis personajes en busca de autor; Cada cual a su manera; Esta noche se improvisa, Romano Luperini (ed.), Madrid, Cátedra, 2004.

UnAMUNO, Miguel de: Ensayos II, Madrid, Aguilar, 1951.

: Teatro completo, Manuel García Blanco (ed.), Madrid, Aguilar, 1959.

: Obras completas, Paisajes y ensayos I, Madrid, Escelicer, 1966.

: Obras completas, Nuevos ensayos III, Madrid, Escelicer, 1968.

: Cartas inéditas de Miguel de Unamuno, Sergio Fernández Larraín (ed.), Madrid, Rodas, 1972.

: Teatro completo, Manuel García Blanco (ed.), Madrid, Aguilar, 1973.

: El otro, El hermano Juan, José Paulino (ed.), Madrid, Espasa-Calpe, 1992.

: Niebla, Armando F. Zubizarreta (ed.), Madrid, Castalia, 1995.

: Obras completas III, Madrid, Biblioteca Castro, 1996.

\section{FUENTES SECUNDARIAS}

CARreto Bautista, Luz M ${ }^{\mathrm{a}}$, y Sota GóMez, Olga $\mathrm{M}^{\mathrm{a}}$ de la: «Niebla, de Miguel de Unamuno Vs. Sei personaggi in cerca d'autore, de Luigi Pirandello», Cuadernos del Lazarillo: Revista literaria y cultural, 29 (2005), pp. 62-66.

Ferraro, Carmine Luigi: «Luigi Pirandello e Miguel de Unamuno fra identità e creazione del personaggio», Artifara: Revista de lenguas y literaturas ibéricas y latinoamericanas, 5 (2005).

MARTÍNEZ-PEÑUELA VIRSEDA, Ana: «Pirandello y Unamuno frente a la locura: Enrique IV y El otro», 1616: Anuario de la Sociedad Española de Literatura General y Comparada, 10 (1996), pp. 197-206.

MOBARAK, Armin: La recepción del teatro extranjero en Madrid (1900-1936), Tesis doctoral, Madrid, Universidad Complutense de Madrid, 2013. 